\title{
Epigenetics of the Synapse in Neurodegeneration
}

\author{
Mary Xylaki $^{1} \cdot$ Benedict Atzler $^{1} \cdot$ Tiago Fleming Outeiro ${ }^{1,2,3}$
}

Published online: 23 August 2019

(C) The Author(s) 2019

\begin{abstract}
Purpose of Review In the quest for understanding the pathophysiological processes underlying degeneration of nervous systems, synapses are emerging as sites of great interest as synaptic dysfunction is thought to play a role in the initiation and progression of neuronal loss. In particular, the synapse is an interesting target for the effects of epigenetic mechanisms in neurodegeneration. Here, we review the recent advances on epigenetic mechanisms driving synaptic compromise in major neurodegenerative disorders.

Recent Findings Major developments in sequencing technologies enabled the mapping of transcriptomic patterns in human postmortem brain tissues in various neurodegenerative diseases, and also in cell and animal models. These studies helped identify changes in classical neurodegeneration pathways and discover novel targets related to synaptic degeneration.

Summary Identifying epigenetic patterns indicative of synaptic defects prior to neuronal degeneration may provide the basis for future breakthroughs in the field of neurodegeneration.
\end{abstract}

Keywords Synapse - Neurodegenerative diseases - DNA methylation · Histone modifications · Noncoding RNAs · Neuroepigenetics

\begin{tabular}{|c|c|}
\hline \multicolumn{2}{|c|}{ Abbreviations } \\
\hline $3 x T g-A D$ & Triple-transgenic AD \\
\hline $5 \mathrm{xFAD}$ & Five familial AD \\
\hline $5 \mathrm{caC}$ & 5-Carboxyl cytosine \\
\hline $5 \mathrm{fC}$ & 5-Formylcytosine \\
\hline $5 \mathrm{hmC}$ & 5-Hydroxymethyl cytosine \\
\hline $5 \mathrm{mC}$ & 5-Methylcytosine \\
\hline $\mathrm{A} \beta$ & Amyloid beta \\
\hline $\mathrm{AD}$ & Alzheimer's disease \\
\hline ALS & Amyotrophic lateral sclerosis \\
\hline BDNF & Brain-derived neurotrophic factor \\
\hline circRNA & Circular RNAs \\
\hline $\mathrm{cDKO}$ & Conditional double knockout \\
\hline
\end{tabular}

This article is part of the Topical Collection on Genetics

Tiago Fleming Outeiro

touteir@gwdg.de

1 Department of Experimental Neurodegeneration, Center for Biostructural Imaging of Neurodegeneration, University Medical Center Göttingen, Waldweg 33, 37073 Göttingen, Germany

2 Max Planck Institute for Experimental Medicine, 37075 Göttingen, Germany

3 Institute of Neuroscience, The Medical School, Newcastle University, Newcastle upon Tyne NE2 4HH, UK

$\begin{array}{ll}\text { CpG } & \text { Cytosine-phosphate-guanine } \\ \text { CpH } & \text { Non-CpG } \\ \text { DNMT } & \text { DNA methylatransferase } \\ \text { EE } & \text { Environmental enrichment } \\ \text { EHMT } & \text { Euchromatic histone methyltransferases } \\ \text { FTD } & \text { Frontotemporal dementia } \\ \text { GWAS } & \text { Genome-wide association studies } \\ \text { H } & \text { Histone } \\ \text { HATs } & \text { Histone acetyltransferases } \\ \text { HD } & \text { Huntington's disease } \\ \text { HDACs } & \text { Histone deacetylases } \\ \text { HDM } & \text { Histone demethylase } \\ \text { HMT } & \text { Histone methyl transferase } \\ \text { htau } & \text { Human tau } \\ \text { lincRNAs } & \text { Large intergenic noncoding RNAs } \\ \text { lncRNAs } & \text { Long ncRNAs } \\ \text { LXR } & \text { Liver X receptor } \\ \text { MD } & \text { Maternal deprivation } \\ \text { miRNAs } & \text { MicroRNAs } \\ \text { Mn } & \text { Manganese } \\ \text { NaB } & \text { Sodium butyrate } \\ \text { ncRNAs } & \text { Noncoding RNAs } \\ \text { Nrf2 } & \text { Nuclear factor erythroid 2-related factor 2 } \\ \text { NSCs } & \text { Neural stem cells } \\ \text { PFC } & \text { Prefrontal cortex }\end{array}$




$\begin{array}{ll}\text { PD } & \text { Parkinson's disease } \\ \text { PTMs } & \text { Posttranslational modifications } \\ \text { RBPs } & \text { RNA-binding proteins } \\ \text { rRNA } & \text { Ribosomal RNA } \\ \text { SAH } & \text { S-Adenosyl homocysteine } \\ \text { SAM } & \text { S-Adenosyl methionine } \\ \text { SAP-102 } & \text { Synapse-associated protein } 102 \\ \text { SYT1 } & \text { Synaptotagmin 1 } \\ \text { TDP-43 } & \text { TAR-DNA binding protein } 43 \\ \text { TET } & \text { Ten-eleven translocation } \\ \text { Tg } & \text { Transgenic } \\ \text { VC } & \text { Vitamin C }\end{array}$

\section{Introduction}

Synapses constitute a highly specialized and vital part of neuronal cells. They are the primary sites of communication between neuronal cells, and therefore, they are involved in all aspects of neuronal physiology. Proper synaptic function is a prerequisite for normal brain function, and even minor disturbances may lead to neurological disorders. In the case of neurodegenerative disorders, these disturbances lead to progressive loss of structural and functional properties of neurons and, eventually, culminate with neuronal death in more or less specific brain regions.

The idea that synaptic dysfunction is evident before neuronal degeneration has been long established and is supported by a large body of literature in various neurodegenerative disorders such as Parkinson's disease (PD) [1], Alzheimer's disease (AD) [2], amyotrophic lateral sclerosis (ALS) [3], or Huntington's disease (HD) [4]. This common denominator in neurodegenerative disorders suggests possible common molecular and/or cellular mechanism for synaptic dysfunction and pathogenesis.

Genetics does not fully explain the vast majority of cases. In PD, AD, and ALS, and, even in HD, the variability in age of onset and clinical manifestations, suggests the involvement of mechanisms that may depend on the interplay with the environment. Therefore, research has also turned to the field of epigenetics (Fig. 1), which may explain subtle changes in synaptic physiology prior to overt neurodegeneration.

Epigenetic mechanisms include any process regulating gene expression without affecting the genome sequence [5]. Conventionally, epigenetic processes comprise the chemical modifications of DNA, histones, and a wide variety of coding and noncoding RNAs, resulting in altered genomic readout and site-specific cellular phenotypes. Epigenetics is a rapidly growing field that pioneered in the study of development, aging, and cancer. In recent years, and owing also to major technological advances in next-generation sequencing, the involvement of epigenetics in neuroscience has been largely investigated. Therefore, the term "neuroepigenetics" appeared in Pubmed in 2009 and has since been widely used in the field. The contribution of epigenetic processes has been investigated in the initiation and progression of neurodegenerative disorders and has often been proposed as target for therapeutic interventions $[6,7]$. Here, we review the most recent advances on our understanding of how epigenetic mechanisms may contribute to synaptic degeneration.

\section{DNA-Associated Epigenetic Processes in Synaptic Degeneration}

DNA methylation is an abundant and widely studied type of epigenetic process. Methylated DNA is mainly inherited [8], but de novo methylation occurs during normal aging, in response to environmental factors, and in disease. Initially, DNA methylation was thought to consist of only 5methylcytosine $(5 \mathrm{mC})$ [9]. This modification has a high prevalence at cytosine-phosphate-guanine $(\mathrm{CpG})$ islands but can also occur in non- $\mathrm{CpG}(\mathrm{CpH})$ sites [10].

$\mathrm{CpH}$ methylation is present predominantly in the neuronal genome and accumulates during synaptogenesis [11]. After neuronal maturation, $\mathrm{CpH}$ methylation is actively maintained in the genome and is thought to restrain transcription [12]. $\mathrm{CpH}$ methylation is reduced in normal brain aging, but the reduction is accelerated in the prefrontal cortex of $\mathrm{AD}$ patients. Interestingly, AD-associated hypomethylation is mostly evident in enhancer regions of $B A C E 1$ and genes encoding tau kinases and CDK5 neuronal activators, which enhance the production of toxic amyloid beta $(\mathrm{A} \beta)$ peptides and are associated with synaptic loss [13••]. Loss of $\mathrm{CpH}$ methylation, accompanied by a general redistribution of methylation spots, is also reported in the parietal cortex of AD patients. Importantly, methylation is increased in the ribosomal RNA (rRNA) promoter, resulting in the silencing of translation, an essential process in synapse physiology [14].

A connection between DNA methylation and the liver X receptor (LXR) transcription factor is identified in AD. In particular, activation of LXR, which is mediated by oxysterols, is downregulated in aging and neurodegenerative diseases proposed as potent therapeutic targets $[15 \bullet \cdot, 16]$. Pharmacological activation of LXR results in significant hypomethylation and restoration of synapse related genes, including synapsin-1, synaptophysin, and synapse- associated protein 102 (SAP-102), in the hippocampus of tripletransgenic $\mathrm{AD}(3 \mathrm{xTg}-\mathrm{AD})$ mice [17].

Manganese (Mn)-mediated epigenetic alterations in neuroblastoma SH-SY5Y cells induce differential expression of PD-associated genes. In particular, elevated Mn results in hypermethylation and downregulation of TH, PARK2, and PINK1. These genes are key players in PD and are related to early synaptic alterations [18-20]. 


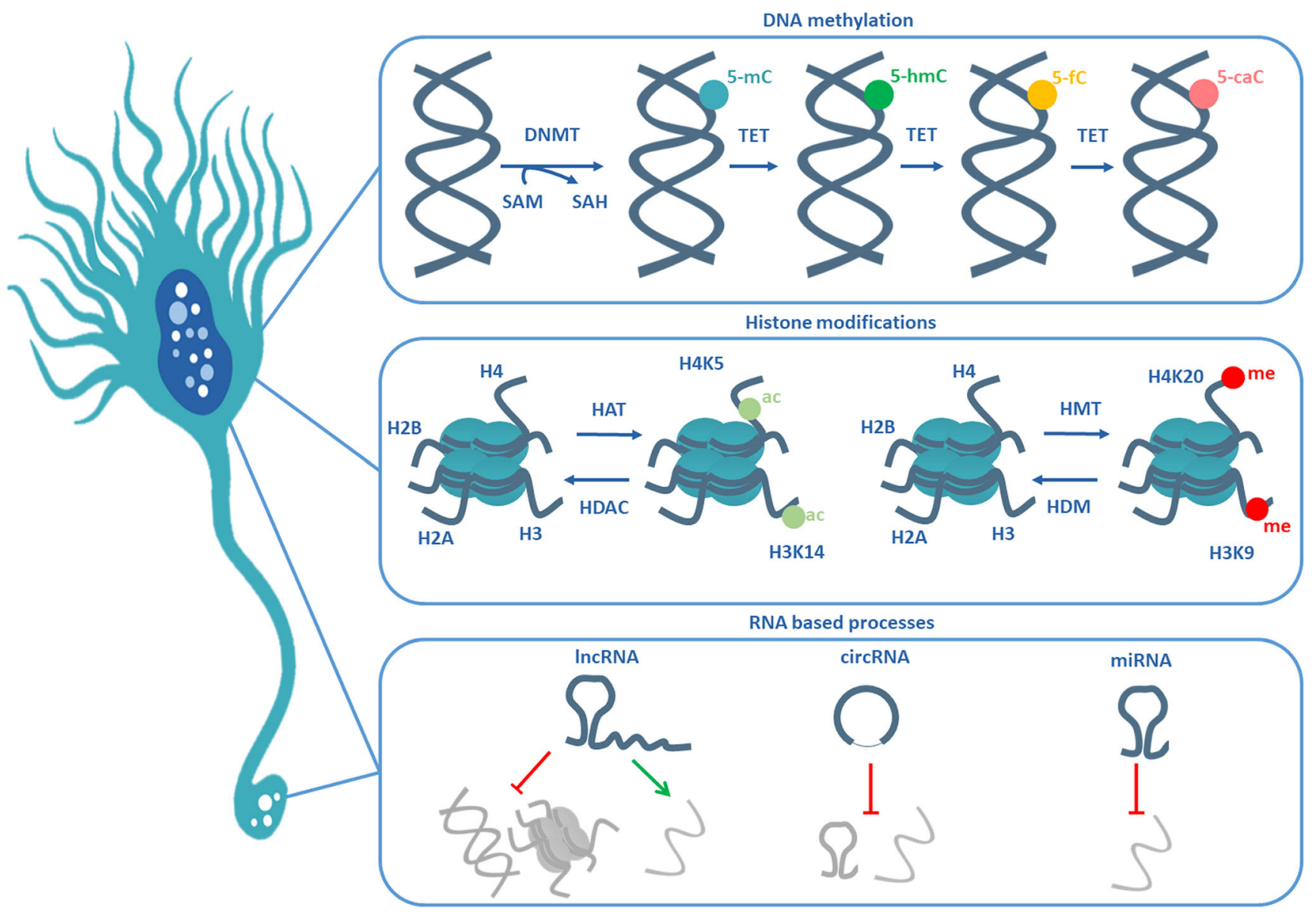

Fig. 1 Epigenetic mechanisms. Epigenetic regulation of gene expression can be mediated by DNA methylation, by histone modifications, or by noncoding RNAs. 5-Methylcytosine $(5 \mathrm{mC})$ is added and controlled by DNA methyltransferase (DNMT) enzymes. This reaction is assisted by the conversion of S-adenosyl (SAM) to S-adenosyl-homocysteine (SAH). Ten-eleven translocation (TET) enzymes oxidize $5 \mathrm{mC}$ to 5 hydroxymethyl cytosine $(5 \mathrm{hmC}), 5$-formylcytosine (5fC), and 5carboxyl cytosine $(5 \mathrm{caC})$, to generate cytosine again, thereby reversing the methylation code. Histone modifications are very diverse and include acetylation and methylation, which are usually installed on lysine residues $(\mathrm{K})$ of one of the histones $(\mathrm{H} 2, \mathrm{H} 3, \mathrm{H} 4)$. Histone modifications are covalent and can be reversible. Acetyl groups (ac) are added by histone acetyltransferases (HATs) and are removed by histone deacetylases (HDACs). Methyl groups (me) are added by histone methyltransferases (HMTs) and are removed by histone demethylases (HDMs). Conventionally, histone acetylation is thought to result in increased transcription, while the effects of methylation depend on the position of the modification. Long ncRNAs (lncRNAs), circular RNAs (circRNAs), and microRNAs (miRNAs) are the most studied RNA-based processes of the nervous system and exert their functions by controlling gene expression and other RNA molecules. LncRNAs can silence genes or whole chromosomes but also activate small RNAs. Circular RNAs act as molecular sponges, collecting and inhibiting mRNAs and microRNAs. MicroRNAs conventionally target complementary mRNAs inhibiting their translation or promoting their degradation

frontal cortex following head-injury-mediated neurodegeneration and is linked to alterations in dendritic structural plasticity [29]. DNMTs catalyze DNA methylation by converting Sadenosyl methionine (SAM) to S-adenosyl homocysteine (SAH). SAH is thought to inhibit DNMTs via a negative feedback loop, and several dietary patterns result in SAH increases that in turn inhibit all three DNMTs [30]. Nutritionally imbalanced diets resulting in high homocysteine levels mediate the increase of SAH in mice and result in significant reductions of all DNMT enzymes, and of DNA methylation. In a mouse model of $\mathrm{AD}$, such diet induces behavioral deficits that are accompanied by a reduction in the levels of synaptophysin and PSD95, and a lower number of synapses [31•]. 
Although $5 \mathrm{mC}$ is very stable, the removal of the methyl group can take place in an active or passive manner, leading to the recovery of nonmethylated cytosine. The passive manner occurs during the replication of repetitive DNA during mitosis and is known as replication-dependent dilution [32]. This does not happen in neurons, since they are postmitotic cells. The active demethylation of $5 \mathrm{mC}$ is mediated by the ten-eleven translocation (TET) proteins that oxidize $5 \mathrm{mC}$ to 5 hydroxymethyl cytosine $(5 \mathrm{hmC}), 5$-formylcytosine $(5 \mathrm{fC})$, and 5-carboxyl cytosine $(5 \mathrm{caC})$ [33]. $5 \mathrm{hmC}$ is highly abundant in the nervous system [34] and, although it does not correlate with neurogenesis and basal neuronal function, it is implicated in more complex processes that require a degree of synaptic plasticity [35]. Enhanced activity of TET and the consequent increase in $5 \mathrm{hmC}$ in dopaminergic neurons result in an increase in the levels of the FOXA2 transcription factor, and in enhanced survival and presynaptic function. In addition, it increases dendritic length and synapse population, as well was dopamine release [36•,37].

\section{Histone-Associated Epigenetic Processes in Synapse Degeneration}

DNA is packed in the nucleus in a condensed polymer that consists of histones $(\mathrm{H} 1 / \mathrm{H} 5, \mathrm{H} 2 \mathrm{~A}, \mathrm{H} 2 \mathrm{~B}, \mathrm{H} 3$, and $\mathrm{H} 4)$ and adaptor proteins, to form chromatin. Histones may undergo posttranslational modifications (PTMs) that alter their structure and biological function. The so-called histone code consists of several different types of PTMs, but 2 of them, acetylation and methylation, are covalent and dynamic [38]. Histone acetylation and deacetylation is mediated by two distinct groups of enzymes: histone acetyltransferases (HATs) and histone deacetylases (HDACs). Conventionally, histone acetylation leads to a more relaxed structure of chromatin and is associated with a higher level of gene expression. Memory consolidation in the hippocampus is tightly linked to gene expression and is often regulated by histone acetylation. The HAT Kat2a is identified in high levels in the hippocampal CA1 region that is affected during neurodegeneration in dementias. Kat2a is a regulator of synaptic plasticity and longterm memory consolidation, in a process mediated by an interaction with NF-KB signaling [39]. The Tip60 HAT is required for neuroadaptive changes induced by environmental enrichment (EE) in the Drosophila CNS mushroom body. Overexpression of Tip60 restores EE-induced benefits in flies overexpressing human APP by hyperacetylation of H4K45 and $\mathrm{H} 4 \mathrm{~K} 12$, leading to increased levels of synaptic proteins and upregulation of genes linked to cognitive function [40]. ANP32A is part of an inhibitory complex masking histone acetylation sites and is upregulated in human tau (htau) transgenic (Tg) mice. In this model, downregulation of ANP32A restores histone acetylation at $\mathrm{H} 3 \mathrm{~K} 9$ and $\mathrm{H} 3 \mathrm{~K} 14$, as well as at
H4K 5 and H4K12, and restores the levels of synaptic proteins, such as synaptophysin, synapsin-1, and glutamate receptor 1 [41]. These results indicate that imbalances in histone acetylation can lead to synaptic changes in various animal models of neurodegeneration.

Increased levels of HDAC2 are observed in AD patients and in mouse models of $\mathrm{AD}$, suggesting that targeting HDAC2 and its partners may rescue neurodegeneration phenotypes $[42,43]$. The transcription factor $\mathrm{Sp} 3$ acts as a cofactor on HDAC2 and facilitates its recruitment to synaptic genes. $\mathrm{Sp} 3$ is upregulated in the brains of $\mathrm{AD}$ patients and in mouse models of neurodegeneration. Specifically, inhibiting the formation of HDAC2-Sp3 complexes rescues synaptic gene expression alterations and function in vitro and in the CK-p25 mouse model of neurodegeneration [44].

Global hypoxia-mediated hippocampal neurodegeneration in rats induces an increase in HDAC2. Accordingly, hypoxic rats show a decrease in H3K9ac and H3K14ac accompanied by a significant decrease in SNAP-25 levels. Treatment with sodium butyrate $(\mathrm{NaB})$, a broad HDAC inhibitor, rescues hypoacetylation as well as SNAP-25 levels, suggesting a regulatory function of HDAC2 in SNAP-25 expression and thus neurotransmitter release $[45,46]$.

The brain-derived neurotrophic factor (BDNF) is known to influence synaptogenesis, synaptic plasticity, and memory consolidation [47, 48] and is decreased in AD patients [49, 50]. Treatment with the universal HDAC inhibitor sulforaphane increases the levels of BDNF and components of the TrkB signaling cascade in mouse primary cortical neurons and $3 \times T g-A D$ mice. The subsequent increase of acetylation of $\mathrm{H} 3$ and $\mathrm{H} 4$ near the P1 promoter of the BDNF gene results in elevated levels of MAP 2 and of the synaptic proteins synaptophysin and PSD-95. These findings suggest an epigenetic effect of sulforaphane that regulates synaptic biology through BDNF signaling [51]. .BDNF is also involved in compromised dopamine signaling upon maternal deprivation (MD) in rats. MD, often linked with neurodegeneration, induces HDAC2 and reduced levels of H3K9ac. Successive elevation of the dendritic spine modulator AKAP150 lowers synaptic levels of protein kinase A and increases mBDNF. These effects can be reverted via HDAC inhibition [52].

Synaptic changes across generations can be observed in the offspring of male wild type mice which performed spatial training. Increased levels of synaptotagmin 1 (SYT1) in the offspring are accompanied by hyperacetylation of $\mathrm{H} 3 \mathrm{~K} 9$ and H3K14 at the SYT1 promoter. These changes do not occur in the offspring of $3 \times \mathrm{Tg}$ AD mice upon paternal spatial training, suggesting impairments of acetylation patterns affecting synaptic plasticity [53].

Histone methylation can lead to upregulation or downregulation of transcription, depending of the exact methylation pattern. Methylation deregulation has been observed in postmortem human samples, in animal models of neurodegenerative 
diseases, and in cell models expressing disease-associated proteins. H3K9me3, H3K27me3, H3K79me3, and H4K20me3 strongly bind the $C 9$ orf 72 promoter. Mutations in $C 9$ orf 72 are the most common cause of familial ALS and frontotemporal dementia (FTD) and are linked with impairments in synapse formation, morphology, and function [54•]. Upon binding to the methylated histones, transcription is reduced and the levels of C9orf72 mRNA levels are decreased in frontal cortices and cerebella of FTD/ALS patients. Treatment with 5-aza-2deoxycytidine, a DNA and histone methylation inhibitor, restores C9orf72 expression in FTD/ALS fibroblasts [55].

$\mathrm{H} 3 \mathrm{~K} 9 \mathrm{me} 2$ is significantly increased in the prefrontal cortex (PFC) of AD patients and in the mouse model expressing five familial AD (5xFAD) mutations. Aged 5xFAD mice display glutamate receptor alterations and impairments in synaptic transmission and memory formation, in a process regulated by an increase in the levels of euchromatic histone methyltransferases EHMT1 and EHMT2 [56•]. In contrast to findings in the $\mathrm{PFC}, \mathrm{H} 3 \mathrm{~K} 9 \mathrm{me} 2$ is decreased in the hippocampal $\mathrm{CA} 1$ region of $\mathrm{AD}$ patients, and ribosomal gene expression is altered in the CA1 and DG regions. The abundance of translation initiation factors is altered prior to neuronal cell death, therefore supporting an early defect in protein synthesis that affects dendritic branches and synapse number [57].

Overexpression of $\alpha$-synuclein, a key player in Parkinson's disease (PD) and other synucleinopathies, is associated with increased levels of H3K9 methylation in Droshophila and in neuroblastoma SH-SY5Y cells. Transcriptional repression through $\mathrm{H} 3 \mathrm{~K} 9 \mathrm{me} 2$ results in a decrease of $L 1 C A M$ and SNAP25 mRNA levels, alterations that might affect synaptic function via deficits in SNARE complex assembly and neurite outgrowth [58].

The importance of a proper methylation "code" is also evident in the context of neural stem cells (NSCs). While NSCs hold a promising potential to differentiate into dopaminergic cells, which might then be used as a replacement therapy for degenerating cells in PD patients, in vitro experiments showed that the neurogenic potential of NSCs declines over time [59]. After treatment with vitamin C (VC), several histones in NSCs are hypomethylated (e.g., H3K9me3, H3K27m3) at marker gene promoter regions (e.g., Foxa 2 and Lmxla), and maintain their neurogenic potential. Additionally, dopaminergic neurons differentiated from VC-treated NCSs show higher levels of synapsin and increased presynaptic dopamine release, suggesting that treatment with VC not only enhances cell survival but also presynaptic function [60•].

\section{RNA-Associated Epigenetic Processes in Synapse Degeneration}

The multitude of forms and functions of RNA are highly attractive and intriguing. From macromolecular machines to small modulators of gene expression, RNAs are extremely important molecules in biology. Strikingly, $98 \%$ of transcribed RNAs are noncoding RNAs (ncRNAs) and are considered to participate in genomic programming [60]. The list of ncRNAs has grown tremendously and is now quite long and diverse, with new functions being assigned to the different classes [61, 62]. Among them, long ncRNAs (lncRNAs), circular RNAs (circRNAs), and microRNAs (miRNAs) are highly enriched in the nervous system [63-65] and have been associated with different aspects of neuronal development, synaptic plasticity, and function, and also with disease [66-68].

Among all epigenetic mechanisms, RNA-based processes are the only ones operating locally at synapses. The first layer of regulation of such processes lays on mechanisms such as RNA transport, local storage, and translation, all of which are dependent on RNA-binding proteins (RBPs) [69].

\section{Long Noncoding RNAs}

LncRNAs are important players in fine tuning brain physiology as they are present in the distal dendritic spines implicated in local active duty $[64,70]$. LncRNAs are greater than $200 \mathrm{nt}$ in size and may be divided in two subclasses: the large intergenic noncoding RNAs (lincRNAs), transcribed from DNA sequences between genes in a manner similar to mRNAs, and the lncRNAs, transcribed from regions within genes [71, 72]. The great potential of lncRNAs is illustrated by their function: lncRNAs can silence small transcripts or entire chromosomes [73] and are proposed to have enhancer function [74]. Recently, a lncRNA, GM12371, identified in mouse hippocampal neurons, was shown to enhance the expression of synapse-related genes and control synaptic morphology and structure [75•].

The identification of such transcriptional regulators of synaptic function may constitute important markers for neurodegenerative disorders. LincRNAs HAO2-AS, EBF3-AS, ADlinc1, and AD-linc2 are upregulated in the hippocampus and entorhinal cortex of AD patients. These transcripts are particularly enriched in the nucleoplasm and are proposed to control histone-associated processes resulting in the downregulation of genes linked to signal transduction and synaptic plasticity, without affecting the levels of genes encoding scaffolding proteins [76]. Another nucleolar IncRNA, LoNA, was found to control translation by suppressing rRNA transcription and methylation, thereby leading to detrimental effects in the synapse. Downregulation of LoNA was found to strengthen memory in wild-type mice and to restore learning and memory deficits in APP/PS1 transgenic animals along with an increase in synaptic markers synaptophysin, PSD95, and glutamate receptors $[77 \bullet \bullet]$.

Several lncRNAs are found deregulated in the substantia nigra of presymptomatic transgenic mice expressing double 
mutated (A30P and A53T) alpha-synuclein. Notably, these deregulated lncRNAs are associated with deficits in synaptic transmission prior to neuronal cell death $[78 \bullet \bullet$.

A surprising function of $\operatorname{lncRNAs}$ was identified in Drosophila melanogaster. In these flies, the lncRNA hrsw was found to physically interact with and retain the RBP FUS in the nucleus. Deletion of hrsw results in translocation of FUS to the cytoplasm and is associated with abnormal architecture of the presynapse of motor neurons [79]. These findings suggest novel molecular mechanisms associated with ALS and other neurodegenerative disorders driven by RBPs [80].

\section{Circular RNAs}

CircRNAs belong to the short class of ncRNAs, as they are shorter than $200 \mathrm{nt}$. CircRNAs are produced in a manner similar to mRNAs, but form a $5^{\prime}$ end to $3^{\prime}$ end covalent bond to form a circle, via an anterograde splicing event [81]. CircRNAs are enriched at synapses and are dynamically altered upon synaptic plasticity $[65,82]$. Our understanding of the functions of circRNAs is expanding but, thus far, they are mainly considered transcriptional regulators acting as sponges sequestering mRNAs and miRNAs besides RBPs [81].

The circRNA for HDAC9 was found to act as a sponge for mir138, which induces synaptic and cognitive impairments in mice. Notably, circHDAC9 is decreased and mir138 upregulated in the APP/PS1 mice [83••].

Interestingly, a cKO mouse model of TAR-DNA binding protein 43 (TDP-43) exhibits deregulation of circRNA processing that is accompanied by deregulation of synaptic proteins associated with plasticity, calcium signaling, and with cognitive function [84・•].

To identify circRNAs involved in neurodegeneration, a mouse model of oxidative stress lacking nuclear factor erythroid 2-related factor 2 (Nrf2) was used. Correlating circRNAs, miRNAs and mRNAs revealed several coregulated partners associated with prion diseases, ALS, AD, and synaptic vesicle cycle regulation [85].

\section{Micro-RNAs}

MiRNAs belong to the class of short noncoding RNAs being 20-23 nucleotides long. They exert their function by complementary binding to mRNA, leading to translation repression or degradation of the target mRNA [86]. Accumulating evidence underscores the importance of miRNAs in synapse development, function and plasticity $[87,88]$. MiRNAs are identified both in pre- and post- synaptic compartment and have been extensively correlated with neurodegeneration $[89,90]$. Synaptosomes isolated from prion protein infected mice prior to the onset of symptoms revealed an upregulation of miR136-5p, miR-361-5p, miR-212-3p, miR-129-2-3p, miR-345$5 p$, and miR-124-3p, facilitating dendrite loss and gliosis [91]. The transcription repressors Bmil, Sox11, and Zfp90 were found to be downregulated by miR-27b, suggesting that this miRNA is a major regulator of the presynaptic transcriptome in mouse cortical neurons.

Upregulation of miR-27b is also correlated with enhanced neurotransmission [92]. There are many clusters of miRNAs that act synergistically towards the establishment of certain phenotypes like the miR-132, miR-134, and miR-138 that regulate neuronal dendrites [93]. Similarly, miR-132 and miR-212 have common regulatory elements and are involved in synaptic transmission and memory formation [94]. The aforementioned clusters of miRNAs show specificity in regulating synaptic structure and function. Therefore, a better understanding of the modes of action of these and other miRNAs may provide novel insight into the molecular basis of various neurodegenerative diseases.

TDP-43 is genetically linked with familial forms of ALS and FTD and is directly implicated in RNA processing. Upon translocation to the cytoplasm, TDP-43 is involved in miRNA processing, and promotes changes in dendritic length and spine morphology that take place prior to neuronal death $[95,96]$. Deep sequencing of post mortem spinal cord tissue from ALS patients revealed a downregulation of miRNAs linked to neuronal processes, such as miR-485, linked with synaptic maintenance, and miR-124 and miR-127, both of which are implicated in neural outgrowth [97].

\section{Conclusions}

Here, we have provided a general overview of recent research on epigenetic-based processes affecting synaptic biology in the context of different neurodegenerative disorders. In short, epigenetic processes can modulate the expression of important components of synaptic function and also of genes directly associated with neurodegeneration.

Epigenetic processes have been now studied for a few years in the context of neurodegenerative diseases and are now starting to be used as targets for therapeutic intervention [98]. However, this field is still young, and requires additional research $[99,100]$. Early epigenetic research focused on discovering modifications in genes identified by genome-wide association studies (GWAS) for the different neurodegenerative diseases [101]. This was initially achieved with the use of DNA microarrays [102] and has more recently progressed to the use of next generation sequencing technologies [103]. Despite tremendous recent progress, it is still unclear how a whole-cell epigenetic effect is directing a specific synaptic phenotype. This question remains still partially unanswered as the interface between epigenetics and synaptic functions 
is currently investigated. Ongoing and future studies will undoubtedly shed light into these processes, and may open novel avenues for therapeutic intervention and even diagnostics in neurodegenerative diseases.

Funding Information Open access funding provided by Max Planck Society. TFO is supported by DFG SFB1286 (Project B6) and was supported by the BMBF Grant Decipher PD (01KU1503B).

\section{Compliance with Ethical Standards}

Conflict of Interest Mary Xylaki, Benedict Atzler and Tiago Fleming Outeiro declare that they have no conflicts of interest.

Human and Animal Rights and Informed Consent This article does not contain any studies with human or animal subjects performed by any of the authors.

Open Access This article is distributed under the terms of the Creative Commons Attribution 4.0 International License (http:// creativecommons.org/licenses/by/4.0/), which permits unrestricted use, distribution, and reproduction in any medium, provided you give appropriate credit to the original author(s) and the source, provide a link to the Creative Commons license, and indicate if changes were made.

\section{References}

Papers of particular interest, published recently, have been highlighted as:

- Of importance

•- Of major importance

1. Schirinzi T, Madeo G, Martella G, Maltese M, Picconi B, Calabresi P, et al. Early synaptic dysfunction in Parkinson's disease: insights from animal models. Mov Disord. 2016;31:802-13.

2. Spires-Jones T, Hyman B. The intersection of amyloid beta and tau at synapses in Alzheimer's disease. Neuron. 2015;82:756-71.

3. Fogarty MJ. Amyotrophic lateral sclerosis as a synaptopathy. Neural Regen Res. Wolters Kluwer - Medknow Publications; 2019.

4. Li JY, Plomann M, Brundin P. Huntington's disease: a synaptopathy? Trends Mol Med. 2003;9:414-20.

5. Dupont C, Armant R, Brenner AC. Epigenetics: definition, mechanisms and clinical perspective. Stem Cell Res Ther. 2016;27: $351-7$.

6. Jakubowski JL, Labrie V. Epigenetic biomarkers for Parkinson's disease: from diagnostics to therapeutics. J Park Dis. 2017;7:1-12.

7. Liu X, Jiao B, Shen L. The epigenetics of Alzheimer's disease: factors and therapeutic implications. Front Genet. 2018;9:1-10.

8. Leonhardt H, Page AW, Weier HU, Bestor TH. A targeting sequence directs DNA methyltransferase to sites of DNA replication in mammalian nuclei. Cell. 1992;71:865-73.

9. Ehrlich M, Gama-sosa MA, Huang L, Midgett RM, Kenneth C, Mccune RA, et al. Amount and distribution of 5-methylcytosine in human DNA from different types of tissues or cells. Nucleic Acids Res. 1982;10:11-4.

10. Woodcock DM, Crowther PJ, Diver WP. The majority of methylated deoxytidines in human DNA are not in the $\mathrm{CpG}$ dinucleotide. Biochem Biophys Res Commun. 1987;145:888-94.
11. Lister R, Mukamel EA, Nery JR, Urich M, Puddifoot CA, Johnson $\mathrm{ND}$, et al. Epigenetic reconfigulation in Mammlian Brain Development. Science (80- ). 2013;341:1-21.

12. Guo JU, Su Y, Shin JH, Shin J, Li H, Xie B, et al. Distribution, recognition and regulation of non-CpG methylation in the adult mammalian brain. Nat Neurosci. 2014;17:215-22.

13.• Li P, Marshall L, Oh G, Jakubowski JL, Groot D, He Y, et al. Epigenetic dysregulation of enhancers in neurons is associated with Alzheimer's disease pathology and cognitive symptoms. Nat Commun. 2019;10:2246 Authors reported hypomethylation of enhancer regions in neurons of $\mathrm{AD}$ patients leading to activation of genes promoting synapse degeneration.

14. Pietrzak M, Rempala GA, Nelson PT, Hetman M. Non-random distribution of methyl-CpG sites and non-CpG methylation in the human rDNA promoter identified by next generation bisulfite sequencing. Gene. 2016;585:35-43.

15.• Di Natale C, Monaco A, Pedone C, Tessitore A, De Mase A, Tedeschi G, et al. The level of 24-hydroxycholesteryl esters decreases in plasma of patients with Parkinson's disease. Neurosci Lett. 2018;672:108-12 This study reports reduced levels of oxysterols in plasma of PD patients proposing a biomarker that may provide a link with DNA hypomethylation levels in neuronal cells.

16. Theofilopoulos S, Arenas E. Liver X receptors and cholesterol metabolism: role in ventral midbrain development and neurodegeneration. F1000Prime Rep. 2015;7:1-8.

17. Sandoval-Hernández AG, Hernández HG, Restrepo A, Muñoz JI, Bayon GF, Fernández AF, et al. Liver X receptor agonist modifies the DNA methylation profile of synapse and neurogenesis-related genes in the triple transgenic mouse model of Alzheimer's disease. J Mol Neurosci. 2016;58:243-53.

18. Tarale P, Sivanesan S, Daiwile AP, Stöger R, Bafana A, Naoghare $\mathrm{PK}$, et al. Global DNA methylation profiling of manganeseexposed human neuroblastoma SH-SY5Y cells reveals epigenetic alterations in Parkinson's disease-associated genes. Arch Toxicol. 2017;91:2629-41.

19. Sassone J, Serratto G, Valtorta F, Silani V, Passafaro M, Ciammola A. The synaptic function of parkin. Brain. 2017;140:2265-72.

20. Stauch KL, Villeneuve LM, Purnell PR, Ottemann BM, Emanuel K, Fox HS. Loss of Pink1 modulates synaptic mitochondrial bioenergetics in the rat striatum prior to motor symptoms: concomitant complex I respiratory defects and increased complex IImediated respiration. PROTEOMICS - Clin Appl. 2016;10: 1205-17.

21. Bestor T, Laudano A, Mattaliano R, Ingram V. Cloning and sequencing of a cDNA encoding DNA methyltransferase of mouse cells. The carboxyl-terminal domain of the mammalian enzymes is related to bacterial restriction methyltransferases. J Mol Biol. 1988;203:971-83.

22. Okano M, Bell DW, Haber DA, Li E. DNA methyltransferases Dnmt3a and Dnmt3b are essential for de novo methylation and mammalian development. Cell. 1999;99:247-57.

23. Feng J, Zhou Y, Campbell SL, Le T, Li E, Sweatt JD, et al. Dnmt1 and Dnmt3a are required for the maintenance of DNA methylation and synaptic function in adult forebrain neurons. Nat Neurosci. 2010;13:423-30.

24. Chouliaras L, Mastroeni D, Delvaux E, Grover A, Kenis G, Hof $\mathrm{PR}$, et al. Consistent decrease in global DNA methylation and hydroxymethylation in the hippocampus of Alzheimer's disease patients. Neurobiol Aging. 2013;34:2091-9.

25. Desplats P, Spencer B, Coffee E, Patel P, Michael S, Patrick C, et al. $\alpha$-Synuclein sequesters Dnmt1 from the nucleus: a novel mechanism for epigenetic alterations in Lewy body diseases. $\mathrm{J}$ Biol Chem. 2011;286:9031-7. 
26. Meadows JP, Guzman-Karlsson MC, Phillips S, Holleman C, Posey JL, Day JJ, et al. DNA methylation regulates neuronal glutamatergic synaptic scaling. Sci Signal. 2015;8:ra61.

27. Pratt KG, Zimmerman EC, Cook DG, Sullivan JM. Presenilin 1 regulates homeostatic synaptic scaling through Akt signaling. Nat Neurosci. 2011;14:1112-4.

28. Petrus E, Lee HK. BACE1 is necessary for experience-dependent homeostatic synaptic plasticity in visual cortex. Neural Plast Hindawi Publishing Corporation; 2014;2014.

29. Mychasiuk R, Hehar H, Ma I, Kolb B, Esser MJ. The development of lasting impairments: a mild pediatric brain injury alters gene expression, dendritic morphology, and synaptic connectivity in the prefrontal cortex of rats. Neuroscience. 2015;288:145-55.

30. Zhang N. Role of methionine on epigenetic modification of DNA methylation and gene expression in animals. Anim Nutr. 2018;4: $11-6$.

31. Li JG, Barrero C, Merali S, Praticò D. Five lipoxygenase hypomethylation mediates the homocysteine effect on Alzheimer's phenotype. Sci Rep. 2017;7:1-12 This study provides a link between elevated homocycteine levels, which is a risk factor for $\mathrm{AD}$, and hypomethylation of important genes for synapse physiology and disease prigression.

32. Smith ZD, Meissner A. DNA methylation: roles in mammalian development. Nat Rev Genet. 2013;14:204-20.

33. Ito S, Shen L, Dai Q, Wu SC, Collins LB, Swenberg JA, et al. Tet proteins can convert 5-methylcytosine to 5-formylcytosine and 5carboxylcytosine. Science (80- ). 2011;333:1300-3.

34. Heintz N, Kriaucionis S. The nuclear dna base 5hydroxymethylcytosine is present in Purkinje neurons and the brain. Science (80- ). 2009;324:929-30.

35. Rudenko A, Dawlaty MM, Seo J, Cheng AW, Meng J, Le T, et al. Tet1 is critical for neuronal activity-regulated gene expression and memory extinction. Neuron. 2013;79:1109-22.

36. Wulansari N, Kim EH, Sulistio YA, Rhee YH, Song JJ, Lee SH. Vitamin C-induced epigenetic modifications in donor NSCs establish midbrain marker expressions critical for cell-based therapy in Parkinson's disease. Stem Cell Rep. 2017;9:1192-206 Authors report $\mathrm{VC}$ mediated reduction of histone methylation resulting in proper development and synaptic health of grafted NSCs in PD brains.

37. Oh S-M, Chang M-Y, Song J-J, Rhee Y-H, Joe E-H, Lee H-S, et al. Combined Nurr1 and Foxa2 roles in the therapy of Parkinson's disease. EMBO Mol Med. 2015;7:510-25.

38. Jenuwein T. Translating the Histone Code. Science (80- ). 2001;293:1074-80.

39. Stilling RM, Rönicke R, Benito E, Urbanke H, Capece V, Burkhardt $\mathrm{S}$, et al. K-lysine acetyltransferase 2a regulates a hippocampal gene expression network linked to memory formation. EMBO J. 2014;33:1912-27.

40. Xu S, Wilf R, Menon T, Panikker P, Sarthi J, Elefant F. Epigenetic control of learning and memory in Drosophila by Tip60 HAT action. Genetics. 2014;198:1571-86.

41. Chai G-S, Feng Q, Wang Z-H, Hu Y, Sun D-S, Li X-G, et al. Downregulating ANP32A rescues synapse and memory loss via chromatin remodeling in Alzheimer model. Mol Neurodegener. 2017;12:34

42. Gonzalez-Zuñiga M, Contreras PS, Estrada LD, Chamorro D, Villagra A, Zanlungo S, et al. c-Abl stabilizes HDAC2 levels by tyrosine phosphorylation repressing neuronal gene expression in Alzheimer's disease. Mol Cell. 2014;56:163-73.

43. Gräff J, Rei D, Guan J-S, Wang W-Y, Seo J, Hennig KM, et al. An epigenetic blockade of cognitive functions in the neurodegenerating brain. Nature. 2012;483:222-6.
44. Yamakawa H, Cheng J, Penney J, Gao F, Rueda R, Wang J, et al. The transcription factor $\mathrm{Sp} 3$ cooperates with $\mathrm{HDAC} 2$ to regulate synaptic function and plasticity in neurons. Cell Rep. 2017;20: 1319-34.

45. Cao T, Zhou X, Zheng X, Cui Y, Tsien JZ, Li C, et al. Histone deacetylase inhibitor alleviates the neurodegenerative phenotypes and histone dysregulation in presenilins-deficient mice. Front Aging Neurosci. 2018;10:137.

46. Biswal S, Das D, Barhwal K, Kumar A, Nag TC, Thakur MK, et al. Epigenetic regulation of SNAP25 prevents progressive glutamate excitotoxicty in hypoxic CA3 neurons. Mol Neurobiol. 2017;54:6133-47.

47. Figurov A, Pozzo-Miller LD, Olafsson P, Wang T, Lu B. Regulation of synaptic responses to high-frequency stimulation and LTP by neurotrophins in the hippocampus. Nature. 1996;381:706-9.

48. Huang EJ, Reichardt LF. Neurotrophins: roles in neuronal development and function. Annu Rev Neurosci. 2001;24:677-736.

49. Connor B, Young D, Yan Q, Faull RL, Synek B, Dragunow M. Brain-derived neurotrophic factor is reduced in Alzheimer's disease. Brain Res Mol Brain Res. 1997;49:71-81.

50. Hock C, Heese K, Hulette C, Rosenberg C, Otten U. Regionspecific neurotrophin imbalances in Alzheimer disease: decreased levels of brain-derived neurotrophic factor and increased levels of nerve growth factor in hippocampus and cortical areas. Arch Neurol. 2000;57:846-51.

51. Kim J, Lee S, Choi B-R, Yang H, Hwang Y, Park JHY, et al Sulforaphane epigenetically enhances neuronal BDNF expression and TrkB signaling pathways. Mol Nutr Food Res. 2017;61: 1600194.

52. Shepard RD, Gouty S, Kassis H, Berenji A, Zhu W, Cox BM, et al. Targeting histone deacetylation for recovery of maternal deprivation-induced changes in BDNF and AKAP150 expression in the VTA. Exp Neurol. 2018;309:160-8.

53. Zhang J, Zhang R, Zhan Z, Li X, Zhou F, Xing A, et al. Beneficial effects of sulforaphane treatment in Alzheimer's disease may be mediated through reduced HDAC1/3 and increased P75NTR expression. Front Aging Neurosci Front Media SA. 2017;9:121

54. Starr A, Sattler R. Synaptic dysfunction and altered excitability in C9ORF72 ALS/FTD. Brain Res. 2018;1693:98-108 Histone methylation linked with impairments in synaptic formation, morphology and function.

55. Belzil VV, Bauer PO, Prudencio M, Gendron TF, Stetler CT, Yan IK, et al. Reduced C9orf72 gene expression in c9FTD/ALS is caused by histone trimethylation, an epigenetic event detectable in blood. Acta Neuropathol. 2013;126:895-905.

56. Zheng Y, Liu A, Wang Z-J, Cao Q, Wang W, Lin L, et al. Inhibition of EHMT1/2 rescues synaptic and cognitive functions for Alzheimer's disease. Brain. 2019;142:787-807 This study shows increased methylation in the prefrontal cortex region of post-mortem tissues of AD patients and correlated the findings with synaptic and cognitive impairments in mice.

57. Hernández-Ortega K, Garcia-Esparcia P, Gil L, Lucas JJ, Ferrer I. Altered machinery of protein synthesis in Alzheimer's: from the nucleolus to the ribosome. Brain Pathol. 2016;26:593-605.

58. Sugeno N, Jäckel S, Voigt A, Wassouf Z, Schulze-Hentrich J, Kahle PJ. $\alpha$-Synuclein enhances histone H3 lysine-9 dimethylation and $\mathrm{H} 3 \mathrm{~K} 9 \mathrm{me} 2$-dependent transcriptional responses. Sci Rep. 2016;6:36328.

59. Studer M, Gavalas A, Marshall H, Ariza-McNaughton L, Rijli FM, Chambon P, et al. Genetic interactions between Hoxal and Hoxb1 reveal new roles in regulation of early hindbrain patterning. Development. 1998;125:1025-36. 
60. Mattick JS. Challenging the dogma: the hidden layer of nonprotein-coding RNAs in complex organisms. BioEssays. 2003;25:930-9.

61. Yan Q, Zhu C, Guang S, Feng X. The functions of non-coding RNAs in rRNA regulation. Front Genet. 2019;10:1-8.

62. Cech TR, Steitz JA. Review the noncoding RNA revolution trashing old rules to forge new ones. Cell. 2014;157:77-94.

63. Derrien T, Johnson R, Bussotti G, Tanzer A, Djebali S, Tilgner H, et al. The GENCODE v7 catalog of human long noncoding RNAs: analysis of their gene structure, evolution, and expression. Genome Res. 2012;22:1775-89.

64. Smalheiser NR, Lugli G, Torvik VI, Mise N, Ikeda R, Abe K. Natural antisense transcripts are co-expressed with sense mRNAs in synaptoneurosomes of adult mouse forebrain. Neurosci Res. 2008;62:236-9.

65. Rybak-Wolf A, Stottmeister C, Glažar P, Jens M, Pino N, Hanan $\mathrm{M}$, et al. Circular RNAs in the mammalian brain are highly abundant, conserved, and dynamically expressed. Mol Cell. 2014;58: 870-85.

66. Smalheiser NR. The RNA-centred view of the synapse: noncoding RNAs and synaptic plasticity. Philos Trans R Soc B Biol Sci. 2014;369:20130504.

67. Briggs JA, Wolvetang EJ, Mattick JS, Rinn JL, Barry G. Review mechanisms of long non-coding rnas in mammalian nervous system development, plasticity, disease, and evolution. Neuron. 2015;88:861-77.

68. Salta E, De Strooper B. Non-coding RNAs with essential roles in neurodegenerative. Lancet Neurol. 2012;11:189-200.

69. Liu-Yesucevitz L, Bassell GJ, Gitler AD, Hart AC, Klann E, Richter JD, et al. Local RNA translation at the synapse and in disease. J Neurosci. 2011;31:16086-93.

70. Glanzer J, Miyashiro KY, Sul J-Y, Barrett L, Belt B, Haydon P, et al. RNA splicing capability of live neuronal dendrites. Proc Natl Acad Sci U S A. 2005;102:16859-64.

71. Ma L, Bajic VB, Zhang Z. On the classification of long noncoding RNAs. RNA Biol. 2013;10:924-33.

72. Guttman M, Amit I, Garber M, French C, Lin MF, Feldser D, et al. Chromatin signature reveals over a thousand highly conserved large non-coding RNAs in mammals. Nature. 2009;458:223-7.

73. Ørom UA, Derrien T, Beringer M, Gumireddy K, Gardini A, Bussotti G, et al. Long noncoding RNAs with enhancer-like function in human cells. Cell. 2010;143:46-58.

74. Dennis MK, Field AS, Burai R, Ramesh C, Whitney K, Bologa $\mathrm{CG}$, et al. Long non-coding RNAs with enhancer-like function in humans. Cell. 2012;127:358-66.

75. Raveendra BL, Swarnkar S, Avchalumov Y, Liu X-A, Grinman E, Badal K, et al. Long noncoding RNA GM12371 acts as a transcriptional regulator of synapse function. Proc Natl Acad Sci. 2018;115:E10197-205 This study reports the identification of a novel InCRNA regulating synaptic function.

76. Magistri M, Velmeshev D, Makhmutova M, Faghihi MA. Transcriptomics profiling of Alzheimer's disease reveal neurovascular defects, altered amyloid- $\beta$ homeostasis, and deregulated expression of long noncoding RNAs. J Alzheimers Dis. 2015;48:647-65.

77.• Li D, Zhang J, Wang M, Li X, Gong H, Tang H, et al. Activity dependent LoNA regulates translation by coordinating rRNA transcription and methylation. Nat Commun. 2018;9. Identification of non coding RNA controling local synaptic translation.

78.• Jiao F, Wang Q, Zhang P, Bu L, Yan J, Tian B. Expression signatures of long non-coding RNA in the substantia nigra of presymptomatic mouse model of Parkinson's disease. Behav Brain Res. 2017;331:123-30 Novel IncRNAs associated with mutant alpha synuclein in presymptomatic PD.
79. Lo Piccolo L, Yamaguchi M. RNAi of arcRNA hsrw affects subcellular localization of Drosophila FUS to drive neurodiseases. Exp Neurol. 2017;292:125-34.

80. Cookson MR. RNA-binding proteins implicated in neurodegenerative diseases. Wiley Interdiscip Rev RNA. 2017;8:e1397.

81. Lasda E, Parker R. Circular RNAs: diversity of form and function. RNA. 2014;20:1829-42.

82. You X, Vlatkovic I, Babic A, Will T, Epstein I, Tushev G, et al. Neural circular RNAs are derived from synaptic genes and regulated by development and plasticity. Nat Neurosci. 2015;18:60310.

83.• Lu Y, Tan L, Wang X. Circular HDAC9/microRNA-138/Sirtuin-1 pathway mediates synaptic and amyloid precursor protein processing deficits in Alzheimer's disease. Neurosci Bull. 2019; Co-regulation of circRNA/mirna/mRNA mediating synaptic function.

84.• Wu LS, Cheng WC, Chen CY, Wu MC, Wang YC, Tseng YH, et al. Transcriptomopathies of pre- and post-symptomatic frontotemporal dementia-like mice with TDP-43 depletion in forebrain neurons. Acta Neuropathol Commun. 2019;7:50 This study identified epigenetic processes regulating synaptic compromise prior to syptom onset.

85. Yang JH, Zhang RJ, Lin JJ, Cao MC, Wang Q, Cui HX, et al. The differentially expressed circular RNAs in the substantia nigra and corpus striatum of Nrf2-knockout mice. Cell Physiol Biochem. 2018;50:952-62.

86. Jonas $\mathrm{S}$, Izaurralde $\mathrm{E}$. Towards a molecular understanding of microRNA-mediated gene silencing. Nat Rev Genet. 2015;16: 421-33.

87. Hu Z, Li Z. miRNAs in synapse development and synaptic plasticity. Curr Opin Neurobiol. 2017;45:24-31.

88. Cohen JE, Lee PR, Chen S, Li W, Fields RD. MicroRNA regulation of homeostatic synaptic plasticity. Proc Natl Acad Sci. 2011;108:11650-5.

89. Lugli G, Torvik VI, Larson J, Smalheiser NR. Expression of microRNAs and their precursors in synaptic fractions of adult mouse forebrain. J Neurochem. 2008;106:650-61.

90. Fiore R, Khudayberdiev S, Saba R, Schratt G. MicroRNA function in the nervous system. Prog Mol Biol Transl Sci. 2011;47100.

91. Boese AS, Saba R, Campbell K, Majer A, Medina S, Burton L, et al. MicroRNA abundance is altered in synaptoneurosomes during prion disease. Mol Cell Neurosci. 2016;71:13-24.

92. Poon VY, Gu M, Ji F, VanDongen AM, Fivaz M. miR-27b shapes the presynaptic transcriptome and influences neurotransmission by silencing the polycomb group protein Bmil. BMC Genomics. 2016;17:1-14.

93. Bicker S, Lackinger M, Weiß K, Schratt G. MicroRNA-132, -134 , and -138: a microRNA troika rules in neuronal dendrites. Cell Mol Life Sci. 2014;71:3987-4005.

94. Hansen KF, Sakamoto K, Aten S, Snider KH, Loeser J, Hesse AM, et al. Targeted deletion of miR-132/-212 impairs memory and alters the hippocampal transcriptome. Learn Mem. 2016;23: 61-71.

95. Figueroa-Romero C, Hur J, Lunn JS, Paez-Colasante X, Bender DE, Yung R, et al. Expression of microRNAs in human post-mortem amyotrophic lateral sclerosis spinal cords provides insight into disease mechanisms. Mol Cell Neurosci. 2016;71:34-45.

96. Handley EE, Pitman KA, Dawkins E, Young KM, Clark RM, Jiang TC, et al. Synapse dysfunction of layer v pyramidal neurons precedes neurodegeneration in a mouse model of TDP-43 proteinopathies. Cereb Cortex. 2017;27:363047. 
97. D'Erchia AM, Gallo A, Manzari C, Raho S, Horner DS, Chiara $\mathrm{M}$, et al. Massive transcriptome sequencing of human spinal cord tissues provides new insights into motor neuron degeneration in ALS. Sci Rep. 2017;7:1-20.

98. Coppedè $\mathrm{F}$. The potential of epigenetic therapies in neurodegenerative diseases. Front Genet. 2014;5:220.

99. Csoka AB, Szyf M. Epigenetic side-effects of common pharmaceuticals: a potential new field in medicine and pharmacology. Med Hypotheses. 2009;73:770-80.3.

100. Rothstein MA, Cai Y, Marchant GE. The ghost in our genes: legal and ethical implications of epigenetics. Health Matrix Clevel. 2009;19:1-62.

101. Harari O, Cruchaga C. Paving the road for the study of epigenetics in neurodegenerative diseases. Acta Neuropathol. 2016;132:483-5.
102. Colyer HAA, Armstrong RN, Mills KI. Microarray for epigenetic changes: gene expression arrays. Methods Mol Biol. 2012:319-28.

103. Guerreiro R, Brás J, Hardy J, Singleton A. Next generation sequencing techniques in neurological diseases: redefining clinical and molecular associations. Hum Mol Genet. 2014;23:R47-53.

Publisher's Note Springer Nature remains neutral with regard to jurisdictional claims in published maps and institutional affiliations. 